\title{
Longitudinal variation of equatorial spread F occurrence over South America
}

R.Y.C. Cueva ${ }^{(1,2) ;}$ Valladares, C. ${ }^{(2)}$; de Paula, E.R. ${ }^{(1)}$; Batista, I.S. ${ }^{(1)}$

1. Divisão de Aeronomia, Instituto Nacional de Pesquisas Espaciais, São José dos Campos, 12227-10, São Paulo, Brazil

2. Institute for Scientific Research, Boston College, EUA.

*Corresponding author: INPE/DAE, Av. dos Astronautas, 1758, Jd. da Granja, 12227-010, São José dos Campos, SP, Brazil; Tel.: +55 12 3208-7255; Fax: +55 12 3208-6990; e-mail: rica_yvan@dae.inpe.br

Copyright 2011, SBGf - Sociedade Brasileira de Geofísica

This paper was prepared for presentation during the $12^{\text {th }}$ International Congress of the Brazilian Geophysical Society held in Rio de Janeiro, Brazil, August 15-18, 2011.

Contents of this paper were reviewed by the Technical Committee of the $12^{\text {th }}$ International Congress of the Brazilian Geophysical Society and do not necessarily represent any position of the SBGf, its officers or members. Electronic reproduction or storage of any part of this paper for commercial purposes without the written consent of the Brazilian Geophysical Society is prohibited.

\begin{abstract}
In this report comparative study has been carried out of the equatorial spread $\mathrm{F}$ longitudinal occurrence characteristics analyzing digisonde data from two longitudinally separate stations and TEC GPS data to get the ionospheric conditions that generate spread F irregularities in the SA continent. Digisonde ionospheric parameters were measured to describe the ionospheric local conditions over São Luís (Brazil) and Jicamarca (Peru) stations, and we found a longitudinal/seasonal/ dayto-day variation in these parameters. To support our finding we use TEC GPS data from Low Latitude lonospheric Sensors (LISN) Network. Using Automatic Bubble Detection Algorithm (ABDA) on TEC data, it was possible to find out bubble signatures (hundreds of kilometers scale size) between September and December months. The bubble occurrence pattern over SA in general follows the characteristics of bubbles detected previously with VHF radar, digisonde and satellite (e.g. DMSP, CHAMP), that are large occurrence on September-October in the west and on December-January in the east. However, we had observed bubble signatures all over the continent among September to December period. Digisonde data from São Luís located at $2.33^{\circ} \mathrm{S}, 44.2^{\circ} \mathrm{W}$ and $1.3^{\circ} \mathrm{S}$ dip latitude, and Jicamarca located at $12.4^{\circ} \mathrm{S}, 77.2^{\circ} \mathrm{W}$ and $1^{\circ} \mathrm{N}$ dip latitude were used to measure the day-to-day longitudinal variation.
\end{abstract}

\section{Introduction}

The ionospheric F layer height conditions near sunset is known to influence the generation of the spread F irregularities, which is well known as several studies explaining its electrodynamics (Farley et al., 1986; Fejer 1997; Fejer et al., 1999; Abdu, 2005). As a summarize, large uplift - Prereversal Enhancement (PRE) - of the evening $F$ layer (that is resurgence of the plasma fountain) can set the preconditions for instability developments or intensification of the Equatorial Spread F - ESF. The instability is believed to be driven by the gravitational Rayleigh-Taylor (GRT) mechanism. The PRE is one of the most important factors as a precursor of Equatorial Spread F (ESF), but not the only one as pointed out by (Kudeki et al., 2007, Tsunoda, 2008).

The pattern behavior of the equatorial plasma ionosphere at different latitudes is well known due to several studies made from particular equatorial stations. Cheng et al. (2006) had made an study of the equatorial ionosphere using a digisonde and GPS receiver over western sector of SA, whereas Abdu et al. (1983a,1983b) had studied the eastern sector with ionosondes. Abdu et al. (1992) and Batista et al. (1990) studied the spread F conditions with ionosonde between eastern and western sectors. The principal finding in these previous works is that the differences in the magnetic field declination angle cause significant differences in the conjugate $E$ region sunset duration, what means it controls the longitudinal and seasonal pattern of the evening spread $\mathrm{F}$ plasma bubble development.

\section{Method}

Digisonde data from two equatorial stations, in the eastern (Jicamarca) and western (São Luís) region of South American continent were used to calculate the vertical drift at 3, 4, 5 and $6 \mathrm{MHz}$ plasma frequency between 1500 and $0300 \mathrm{LT}$. The results at different frequencies are generally comparable during evening hours when $\mathrm{F}$ layer rises up under the prereversal enhancement in the zonal electric field (Abdu et al., 2009). We use fifteen-minute data during magnetically quiet days on equinox and summer solstice, from low solar minimum conditions (2009), and average of $76 \mathrm{sfu}$ (10.7cm solar flux). 
VTEC data from 4 different GPS networks at South America (see Fig.1) is used to detect bubbles. To detect bubbles we use the Automatic Bubble Detection Algorithm (ABDA) developed by ISR-BC, that use GPS VTEC to calculate depletion and to find out bubbles observed by the receiver. Detecting depletion in the VTEC is the indirect way to find bubbles of hundreds of kilometers scale size. This technique is very well documented at Valladares et al. (2004a) and Seemala et al. (2011) (in development). Figure 1 shows the networks (LISN in green dots and 3 more networks in red dots) used in this study.

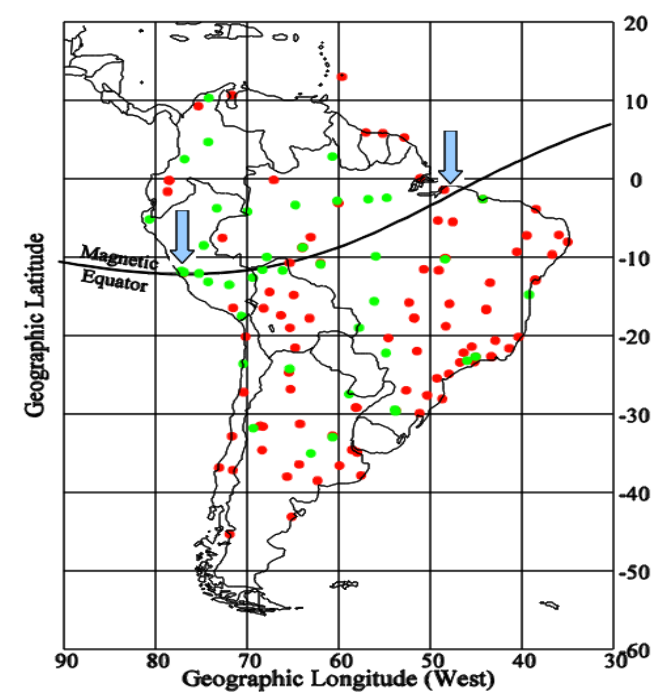

Figure 1. LISN GPS Network (in green) \& 3 more Networks (in red). The blue arrows are indicating the Jicamarca (Peru) and São Luís (Brazil) stations. Shown are the magnetic field lines crossing the magnetic equator at longitudes of $70^{\circ} \mathrm{W}, 60^{\circ} \mathrm{W}$ and $50^{\circ} \mathrm{W}$.

\section{Data Analysis}

We chose the months of September to December 2009 due to the high bubble presence over South American region. The bubble presence during equinox over Jicamarca is September-October and over São Luís is November-December period (Abdu et al., 1981, de Paula et al., 2007). We made the manual scaling of the digisonde data of each station using the University of Massachusetts Lowell Application SAO Explorer (version 3.4.15).

During local sunset times the HmF2 take values that increase from $\sim 300 \mathrm{~km}$ to $>400 \mathrm{~km}$ since October to December in São Luís, and approximately same behavior at Jicamarca from September to October. The NmF2 and foF2 (doesn't show here) parameters from both stations have very low values around the local sunrise and high values around 15 hours LT.

Figures 2 and 3 show the variability of the digisonde parameters (HmF2 and NmF2) between September and December 2009 for both stations, respectively. These figures are in Universal Time, but if we change them in Local Time (do not showed here) they will present the identical general behavior, with very low values at sunrise, very high values around local noon and a second peak (but less than later one) around sunset, in the HmF2. The NmF2 shows low values prior to sunrise, and high around 15 hours LT for both stations. So it is possible to observe in these figures that in Jicamarca between October and November there is a double crest formation (in density) during daytime around 13 and 21 UT. In Fortaleza is observed a very high peak (PRE) on October around 18 hours UT. This oscillation found in frequency (foF2) along the day were reported previously by McNamara et al. (2008) using ionosonde data from COPEX campaign at solar maximum and also reported by Batista et al. (1989) using digisonde data from Fortaleza and Huancayo at high solar activity. 

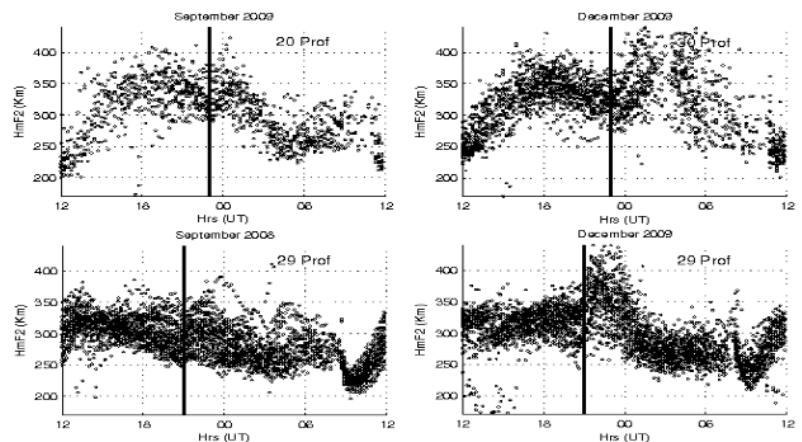

Figure 2. HmF2 parameter for Jicamarca (upper panels) and São Luís (lowest panels) from September and December 2009. Vertical bar represents the local sunset.
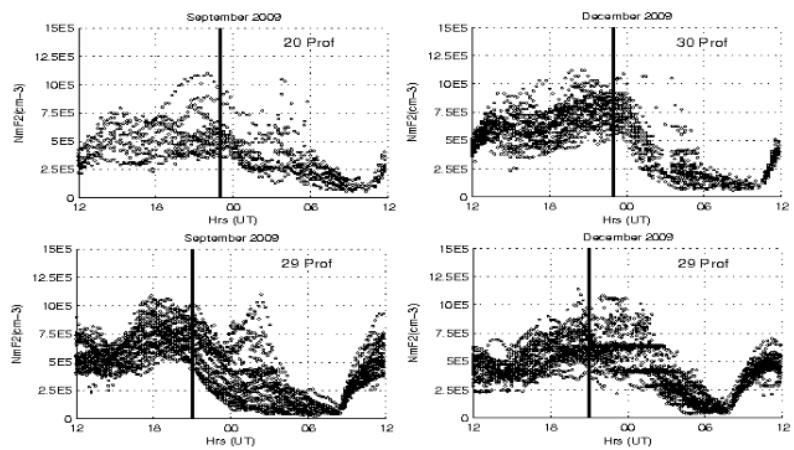

Figure 3. NmF2 parameter from Jicamarca (upper panels) and São Luís (lowest panels) from September and December 2009. Vertical bar represents the local sunset.

The HmF2 over São Luís station held lower than $300 \mathrm{~km}$ before afternoon time (the electrodynamics developed here permits the nighttime control of the $\mathrm{F}$ region) around September, and then increase the altitude of the $\mathrm{F}$ layer becoming over $300 \mathrm{~km}$ at afternoon time ( $\sim 15 \mathrm{LT}$ to $\sim 18 \mathrm{LT})$ during November to December period. This parameter over Jicamarca station held up to $300 \mathrm{~km}$ during September and October in afternoon time, and around $300 \mathrm{~km}$ between November and December at afternoon time.

The NmF2 (proportional to foF2) parameter presents two crests over São Luís between October to December and is highlighted by gray bars, as shown in Figure 3. Over Jicamarca these two crests are observed on September to October. After removing days with low or null presence of bubbles the behavior shown in Figures 3 and 4 doesn't change (not shown in this report), meaning that this oscillation is not relevant to bubble presence, and because was also observed at maximum solar (McNamara et al., 2008 and Batista et al., 1989).

During 2009 the magnetic activity remained quiet during this extended solar minimum, but even so we had bubble formation all over the continent. The data were analyzed during low magnetic activity with low Kp (sum of entire day) all over the period here studied, and very low monthly mean solar $10.7 \mathrm{~cm}$ flux (F10.7), of $76 \mathrm{sfu}$. Bubble presence were observed with GPS LISN network (Valladares et al., 2004a,b), and we had separated by east and west bubble presence in each region. We are focusing our study in the sunset time, and we are joining September with October and November with December to analyse the behavior of Jicamarca and São Luís separate like observed at Figures 4 and 5. 
Figure 4. Altitude calculated with frequencies $3-4 \mathrm{MHz}$ (red and blue, respectively) on the top panels and $5-6 \mathrm{MHz}$ (red and
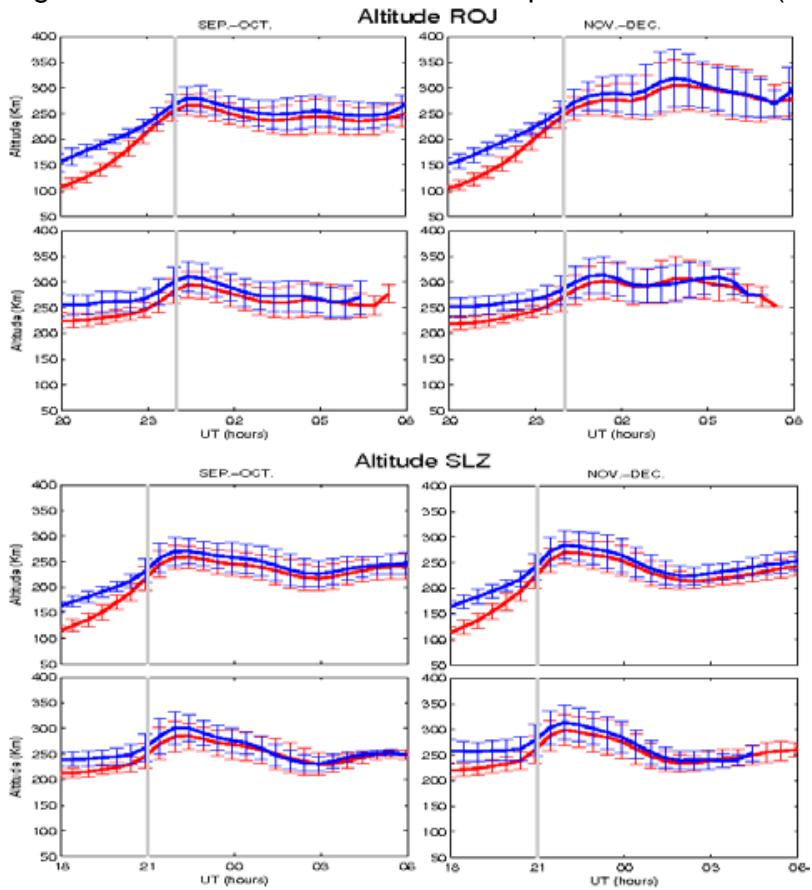

blue, respectively) on the bottom for Jicamarca (on the top) and São Luís (on the bottom).

We calculated the Vertical Drift Velocity using the ratio of altitude and time variation of $30 \mathrm{~min}$. $(\Delta \mathrm{H} / \Delta \mathrm{t})$ around the local sunset (1500 to 0300 LT). For manually scaling the digisonde data we made with $15 \mathrm{~min}$. resolution, and for the average here presented we used $30 \mathrm{~min}$. resolution. The altitudes from each frequency $(3,4,5$ and $6 \mathrm{MHz})$ were obtained using the SAO explorer program after the manual scaling of the data, and now presented as function of Universal Time on Figures 4 and 5 , and centered on 1500 to 0300 LT. All the panels are monthly mean and with the respective error bar, showing separately values for 3 and $4 \mathrm{MHz}$ (red and blue, respectively) on the top panels and 5 and $6 \mathrm{MHz}$ (red and blue, respectively) on the bottom panels. The vertical gray bar represents the local sunset of each station.

\section{São Luís:}

The vertical drift velocity reaches the peak velocity almost at the same time in both periods, but the velocity is little high in Nov-Dec period and also the altitude of the peak altitude is higher than Sep-Oct period. The bubble occurrence is all over this two periods and is getting higher close to summer solstice (December-January). And we could expect that in January the altitude and velocity peak should be higher (but not processed here) than December (de Paula et al., 2007).

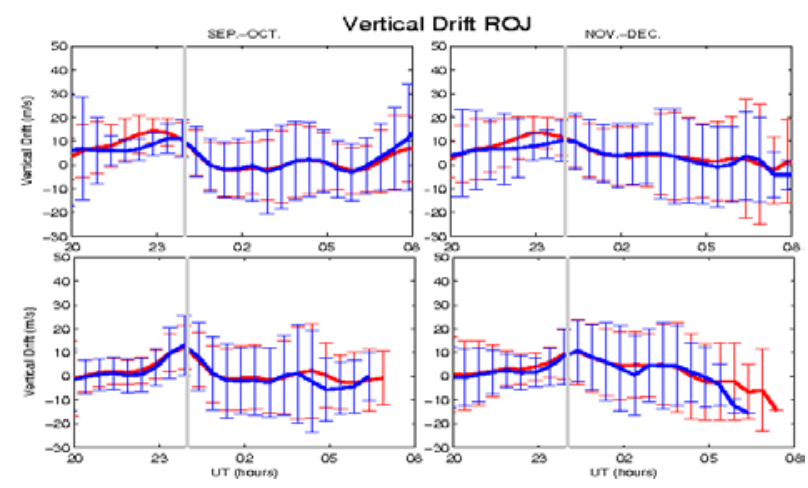




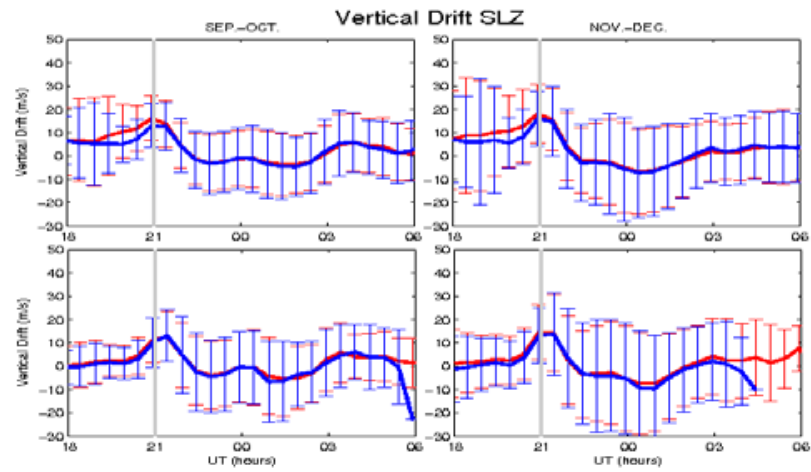

Figure 5. Vertical drift for Jicamarca (top panels) and São Luís (bottom panels) stations. Velocity calculated for 3-4MHz (red and blue, respectively) and 5-6MHz (red and blue, respectively).

\section{Jicamarca:}

The vertical drift velocity reaches faster the peak velocity at local sunset at frequencies 5-6MHz over Sep-Oct months, and for Nov-Dec months reaches the peak velocity slowly. During Sep-Oct the altitude peak is reached after the local sunset, then the altitude become to decrease. During Nov-Dec period the altitude peak observed at $5-6 \mathrm{MHz}$ is also reached after local sunset, and after an small decrease it continue to increase up to local midnight and in $3-4 \mathrm{MHz}$ is possible to see a highest peak around 0004UT of 325km.

Analysis is made in cases we do have/don't have bubble presence, as detected in the VTEC using ABDA, and comparing digisonde parameters (HmF2,NmF2 and vertical drift) of both stations when bubbles were observed over the east region, west region and all over the continent. This comparison will give us an idea of how these two longitudinal stations $\left(38,9^{\circ}\right.$ and 2 hours separation) and nearly to the magnetic equator can show high day-to-day variability. A decrease in NmF2 and simultaneous increase in $\mathrm{HmF} 2$ at sunset time means formation of the anomaly, and prereversal enhancement which will imply in TEC depletions as explained by Kelley (1989) and Fejer et al. (1997).

An example of TEC GEP data used in the analysis is in Figure 6, where it is possible to see the bubbles detected (small lines all over the continent) in different hours (color code). We got this bubble detection using ABDA developed at Boston College by Cesar Valladares group. 


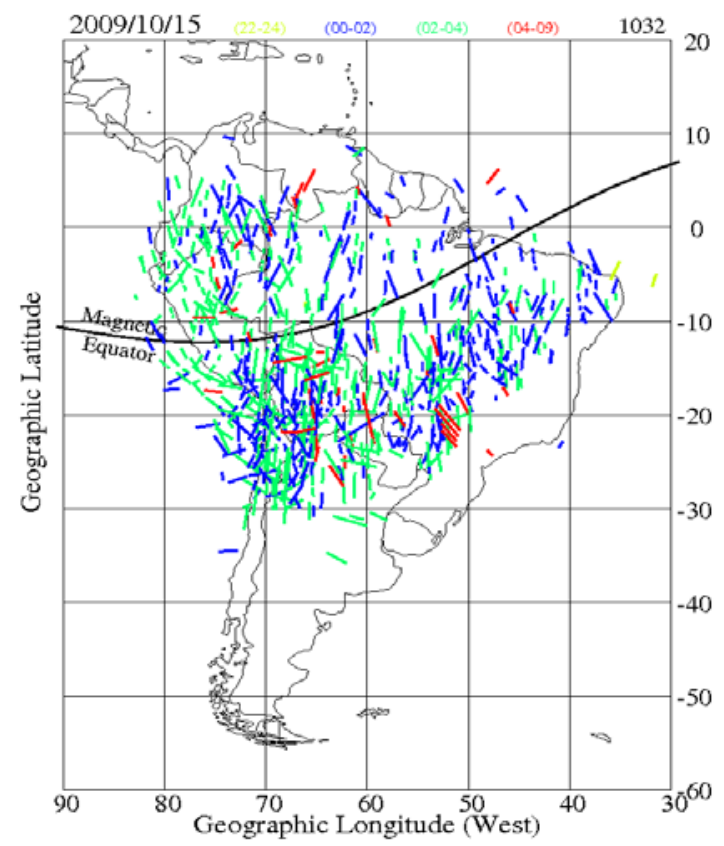

Figure 6. Bubbles detected over South America during October 15, 2009 using TEC data from LISN Network.

We had observe that for the same day (Oct. 15, 2009) the PRE is present as a mechanism generator of TEC depletions/bubbles. In other cases, we had also observed (not showed here) that there are some days with no PRE and with bubbles detected, and some days with PRE and bubbles not detected as if them were inhibited. This variation is observed from month-to-month and day-to-day.

Comparing bubbles detected (as in Figure 6) with drift velocity (as in Figure 4 and 5) we proved that in September 2009, over Jicamarca, we have $40 \%$ of days with PRE when TEC depletions are observed and $46 \%$ of days with no PRE and presence of TEC depletions. On December 2009, over Jicamarca, the 100\% of cases with PRE present TEC depletions were observed and none days with no PRE and TEC depletions, which means that PRE is very effective this month. The remaining percentage from PRE or no PRE have no TEC depletions. Meanwhile over São Luís, on November 100\% of days with PRE and no PRE have TEC depletions detected, and on October 100\% of cases with PRE have TEC depletions and $82 \%$ of no PRE have TEC depletions. This means that PRE is a necessary but not sufficient mechanism for ESF formation, and that there is another mechanism associated with bubble occurrence.

\section{Conclusions}

Spread F occurrence over Jicamarca have high bubble and ESF occurrence on Sept-Oct and over São Luís is in Nov-Dec (according our data). And the PRE seems to be a good favoring mechanisms for ESF at both stations.

However, over São Luís there is probably another favoring/seeding mechanism associated with bubbles occurrence that is not related with PRE since doesn't present the initial conditions.

This results prove that PRE is a favoring mechanism as we had known since Farley et al. (1986), but now not the only one. As cited by Tsunoda (2008) and Kudeki et al., (2007) there are also the Large Scale Wave Structures (LSWS) and vortex due to the wind, and also the Gravity Waves as favoring generators of the conditions to develop ESF/bubbles (de Paula et al., 2011).

The difference observed in percentage of bubbles detected and PRE observed is presumably due to the high magnetic declination angle presented in the Brazilian region. In Jicamarca the declination is almost zero, and São Luís is around 12S. A possible influence of the large negative declination angles over Brazil should be considered as one of the responsible by the stronger TEC over São Luís, once that the declination angle is supposed to be the causative of the modifications in the equatorial electrojet (Shume et al., 2010) and the EEJ is the main responsible by the daytime vertical drift. 


\section{References}

[1] Abdu et al., 1981.Magnetic declination control of the equatorial F region dynamo electric field development and spread F. JGR Vol. 86, No. A13, Pages 11,443 -11,446.

[2] Abdu et al., 1998: Equatorial spread-F occurrence statistics in the American longitudes: diurnal, seasonal and solar cycle variations. Adv. Space Res.

[3] Abdu et al., 1992. A new aspect of Magnetic Declination Control of Equatorial Spread F and F Region Dynamo. JRG Vol. 97, No. A10, Pages 14,897-14,904.

[4] Abdu M.A. 2005. Equatorial ionosphere-thermosphere systems: Electrodynamics and irregularities. Vol. 35, Pages 771787.

[5] Abdu et al., 2009. Equatorial evening prereversal vertical drift and spread $\mathrm{F}$ suppression by disturbance penetration electric fields. GRL, Vol. 36, L19103, doi:10.1029/2009GL039919.

[6] Batista, I.S. et al., 1996. Equatorial ionospheric vertical plasma drift model over the Brazilian region. JGR, Vol.101, No. A5, Pages 10,887-10,892.

[7] Batista et al., 1990: Magnetic activity effects on range type spread-F and vertical plasma drift at Fortaleza and Huancayo as studied through ionosonde measurements and theoretical modeling. Ann.Geophys.

[8] de Paula et al., 2007. Characteristics of the ionospheric F-region plasma irregularities over Brazilian longitudinal sector. IJRSP Vol. 36, August 2007, Pages 268-277.

[9] de Paula et al., 2011. Observations of pre-midnight 5-m irregularities in the equatorial F region over São Luís, Brazil: Solar-flux dependence and seasonal variations. Doi:10.1016/j.jastp.2011.03.014 (Paper acepted at journal JASTP).

[10] Farley et al., 1986. The Prereversal Enhancement of the Zonal Electric Field in the Equatorial Ionosphere. JGR Vol. 91, No. A12, Pages 13,723-13,728.

[11] Fejer et al., 1995. Global equatorial ionospheric vertical plasma drifts measured by the AE-E satellite. JGR Vol. 100, No A4, Pages 5769-5776.

[12] Fejer B.G. JASTP 1997. The electrodynamics of the low-latitude ionosphere: recent results and future challenges. Vol. 59, No. 13, Pages 1465-1482.

[13] Hoang T.L. et al., 2010. Longitudinal differences in the equatorial spread F characteristics between Vietnam and Brazil. Adv.Space Res.

[14] Kelley, M. C. 1989. The Earth's ionosphere: Plasma physics and electrodynamics. International Geophysics Series, vol 43. San Diego: Academic Press.

[15] Kudeki et al., 2007. Equatorial spread F initiation: Post-sunset vortex, thermospheric winds, gravity waves. JASTP 69, Pages 2416-2427.

[16] McNamara, L.F. et al., 2008. F2 parameters, drift and spread F derived from digisonde ionograms for the COPEX campaign in Brazil.

[17] Reinisch, R.W. et al., 2004. Multistation digisonde observations of equatorial spread F in South America. AnnGeo

[18] Sales, G.S. et al., 1996. Spread F and the structure of equatorial ionization depletions in the Southern anomaly region. JGR

[19] Shume, E. B. et al., 2010. Variabilities of the equatorial electrojet in Brazil and Perú , JGR, Pg.115 ,A06306.

[20] Su, S.-Y. et al., 2008. On monthly/seasonal/ longitudinal variations of equatorial irregularity occurrences and their relationship with the postsunset vertical drift velocities. JGR, Vol. 113, A05307, doi:10.1029/2007JA012809.

[21] Tsunoda, Roland T. GRL 2008. Satellite traces: An ionogram signatures for large-scale wave structure and a precursor for equatorial spread F. Vol. 35, L20110, doi:10.1029/2008GL035706.

[22] Valladares et al. Latitudinal extension of low-latitude scintillation measured with a network of GPS receivers. AnnGeo 2004a, 22:3155-3175

[23] Valladares et al. A latitudinal network of GPS receivers dedicated to studies of equatorial spread F. Radio Science 2004b, Vol. 39, RS1S23. 
